\title{
ASSOCIAÇÃO ENTRE A ANÁLISE SOROLÓGICA E A REAÇÃO EM CADEIA DA POLIMERASE (PCR) NO DIAGNÓSTICO DA INFECÇÃO PELO Mycoplasma hyopneumoniae EM SUÍNOS DURANTE PROCEDIMENTO DE QUARENTENA
}

\section{Association between the serologic analysis and the polymerase chain reaction $(P C R)$ in the diagnostic of the Mycoplasma hyopneumoniae infection in pigs during quarantine procedure}

\author{
ROCHA, D.L. ${ }^{1}$; COSTA, W.M. ${ }^{1}$; RABELO, M. ${ }^{1}$; SANTOS, J.L. ${ }^{1}$; ALBERTON, G.C. ${ }^{2}$ \\ ${ }^{1}$ Médico Veterinário - Microvet. \\ ${ }^{2}$ Professor, Departamento de Medicina Veterinária/UFPR.
}

Endereço para correspondência: Danilo Leal Rocha: dleal@terra.com.br

\section{RESUMO}

Investigou-se por meio de análises sorológicas e pela técnica da reação em cadeia da polimerase (PCR) a presença do Mycoplasma hyopneumoniae em fêmeas reprodutoras suínas durante 0 procedimento de quarentena. $O$ estudo foi realizado em um lote de 300 fêmeas da linhagem Landrace x Large White de 150 dias de idade em uma unidade de quarentena no estado do Paraná no ano de 2007. Os animais foram provenientes de uma única granja, sendo esta, considerada livre do Mycoplasma hyopneumoniae. Os exames foram realizados no laboratório Microvet localizado em Viçosa-MG. Não foram observados sinais clínicos sugestivos de problemas respiratórios bem como não foi detectado soroconversão para o $M$. hyopneumoniae nas 130 análises sorológicas, realizadas em amostras de soro coletadas nos dias 0, 55 e 76 após o alojamento dos animais. Entretanto, o M. hyopneumoniae foi detectado por meio da PCR (fragmento de $649 \mathrm{pb}$ do gente rRNA 16S) de lavado traqueobronqueal e tecido pulmonar de uma fêmea com análise sorológica não conclusiva na amostra coletada no dia 55 após o alojamento. Desta forma, a associação entre as análises sorológicas e a PCR foi importante no diagnóstico do Mycoplasma hyopneumoniae durante o procedimento de quarentena.

Palavras-chave: biossegurança; PCR; pneumonia enzoótica; soroconversão; sorologia

\begin{abstract}
This study investigated through serologic analysis and polymerase chain reaction (PCR) the presence of Mycoplasma hyopneumoniae in reproductive gilts during quarantine proceeding. This study was realized in 300 Landrace x Large White gilts with 150 days of age in a quarantine unity in Parana in 2007. These animals came from a single farm, considered free from Mycoplasma hyopneumoniae. The exams were made at Microvet laboratory located in Viçosa-MG. Clinical signs that suggest of respiratory problems were not seen, nor seroconversion was detected in 130 serologic analysis, performed in serum samples collected on days 0,55 and 76 after housing, however, the Mycoplasma hyopneumoniae was detected through PCR (649 bp fragment of 16S gene) in tracheobronchiolar wash and pulmonary tissue from a gilt without conclusive result in serologic analysis in a sample collected 55 days after housing. Hence, association between serologic analysis and PCR was important to diagnose Mycoplasma hyopneumoniae during quarantine proceedings.
\end{abstract}

Key words: biosecurity; enzootic pneumoniae; PCR; seroconversion; serology 


\section{INTRODUÇÃO}

O Mycoplasma hyopneumoniae é o agente da pneumonia enzoótica e desempenha importante função no complexo de doenças respiratórias dos suínos (Thacker et al., 1999; Kim et al., 2003). A pneumonia enzoótica é altamente prevalente na população de suínos no mundo e é caracterizada por alta morbidade e baixa mortalidade (Thacker, 2006; Maes et al., 2008). Este agente pode causar reduções nas taxas de conversão alimentar, crescimento e maior predisposição a infecção por outros agentes infecciosos respiratórios, sendo assim, um dos agentes infecciosos de maior impacto econômico na produção de suínos (Fano et al., 2005; Lin et al. 2006; Maes et al., 2008).

A principal forma de introdução do $M$. hypneumoniae nos rebanhos é pela aquisição de reprodutores portadores assintomáticos (Thacker, 2006; Maes et al. 2008). Desta forma, rebanhos livres deste agente, além de adquirir reprodutores de granjas consideradas livres, adotam procedimento de quarentena. Durante a quarentena os animais são submetidos à avaliação clínica e exames laboratoriais, tais como análises sorológicas (Sorensen et al., 1997; Erlandson et al., 2005; Maes et al., 2008) e a reação em cadeia da polimerase (Blanchard et al., 1996; Artiushin et al., 1993; Calsamiglia et al., 2000; Moorkamp et al., 2008) para detectar indícios de infecção pelo $M$. hyopneumoniae. Apesar deste rígido protocolo de quarentena, rebanhos têm se tornado positivos para $0 \quad M$. hyopneumoniae após a introdução de reprodutores.

O objetivo deste estudo é apresentar um diagnóstico positivo, por meio de análise sorológica e reação em cadeia da polimerase (PCR), para $0 \quad M$. hyopneumoniae durante procedimento de quarentena, assim como discutir pontos relevantes relacionados ao diagnóstico de
M. hyopneumoniae para auxiliar na elaboração de protocolos de investigação mais eficientes.

\section{MATERIAL E MÉTODOS}

O estudo foi realizado no município de Castro no estado do Paraná no ano de 2007 durante procedimento de quarentena de um lote de fêmeas suínas da linhagem Landrace $\mathrm{x}$ Large White para reposição do plantel. A unidade de quarentena era isolada por cerca viva composta por eucaliptos, cerca de arame e barreira sanitária para banho e troca de roupas. $\mathrm{O}$ funcionário era exclusivo desta unidade e eram controlados os acessos de pessoas e veículos. Esta unidade estava limpa, desinfetada e sem contato com suínos há 45 dias. Todo o dejeto das canaletas foi retirado antes dos procedimentos de limpeza e desinfecção.

O lote avaliado foi composto por 300 fêmeas de 150 dias de idade, sendo que estas foram alojadas em grupos de 10 fêmeas por baia (1,0 $\mathrm{m}^{2} /$ fêmea). A ração e a água foram fornecidas a vontade. De acordo com a empresa fornecedora dos reprodutores foram realizadas monitorias clínicas e sorológicas na granja de origem, sendo esta, considerada livre do $M$. hyopneumoniae. Por medidas técnicas de biossegurança o fornecedor de reprodutores não permite visita à granja para avaliação clínica e exames laboratoriais.

Durante o período de quarentena foram realizadas três visitas, nos dias 0,55 e 76 após o alojamento. Nestas visitas, foram realizadas criteriosas avaliações clínicas do lote. Antes da realização dos procedimentos de coleta, os animais foram avaliados por 30 minutos para observação de sinais clínicos sugestivos de problemas respiratórios, tais como espirro, tosse, dispnéia e apatia. Estas avaliações permaneciam durante os procedimentos de coleta, de forma que, podendo-se conside- 
rar duas horas como período de avaliação clínica.

As análises sorológicas foram realizadas com o kit DAKO ${ }^{\circledR}$ Mh ELISA (DAKO, Glostrup, Denmark, $\mathrm{n}^{\circ}$ de série 530903). As reações foram realizadas conforme orientações do fabricante, sendo, todas as análises sorológicas realizadas com controle positivo e negativo para validação. Os resultados foram lidos em espectrofotômetro com comprimento de onda de $450 \mathrm{~nm}$. Amostras de soro com valores de densidade óptica (DO) $<50 \%$ da $\mathrm{DO}_{\text {controle }}$ foram consideradas positivas enquanto que valores de $\mathrm{DO}>65 \%$ da $\mathrm{DO}_{\text {controle }}$ foram consideradas negativas. Amostras de soro com valores de DO entre 50 a $65 \%$ da $\mathrm{DO}_{\text {controle }}$ foram consideradas não conclusivas, sendo que, novas amostras destes mesmos animais foram coletadas três semanas posteriores para repetição das análises sorológicas.

O número de animais selecionados para a coleta de sangue e análises sorológicas foi definido em função do número de animais no lote, considerando uma prevalência estimada em $5 \%$ e um nível de confiança de 95\%. Desta forma, foram realizadas coletas de sangue em 60 fêmeas no dia 0 e 60 fêmeas no dia 55 após o alojamento. No dia 76 foram realizadas coletas de sangue em 10 fêmeas, sendo, três com resultado da DO entre 50 a $65 \%$ da $\mathrm{DO}_{\text {controle }}$ (resultados não conclusivos) nas análises sorológicas das amostras coletadas no dia 55 e sete amostras de fêmeas em contato direto com estes animais. Para a coleta de sangue foram utilizadas seringas $(10 \mathrm{~mL})$ e agulhas (40x12) descartáveis, sendo retirado $10 \mathrm{~mL}$ de sangue por venopunção da veia cava superior. $O$ sangue foi centrifugado a $10.000 \times \mathrm{g}$ por 15 minutos, o soro foi separado, armazenado em tubo Eppendorf de $2 \mathrm{~mL}$ e congelado a $-20^{\circ} \mathrm{C}$. As amostras devidamente acondicionadas foram enviadas ao laboratório para as análises sorológicas.
No dia 76 após o alojamento também foi realizada eutanásia e necropsia de uma das três fêmeas com resultado não conclusivo nas análises sorológicas das amostras coletadas no dia 55. Para isto, foi selecionada a fêmea com a amostra de soro com a leitura da DO mais próximo a $50 \%$ (positivo). Para realização da eutanásia foi utilizada a eletrocussão e exanguinação na veia cava superior. Foram coletados traquéia, brônquios, bronquíolos e pulmão, armazenados em saco plástico e mantidos numa caixa isotérmica para envio ao laboratório, sendo que todo material utilizado neste procedimento era descartável.

Para a extração de DNA total foi utilizada a técnica descrita por Davis et al. (1994), realizado em pool de lavado traqueobronqueal e tecido pulmonar. A reação de nested-PCR (nPCR) foi realizada para detectar um fragmento do gene rRNA 16S de tamanho de $649 \mathrm{pb}$ especifico para $M$. hyopneumoniae. O método foi realizado utilizando oligonucleotideos previamente descritos por Mattson et al (1995). A mistura de reação para amplificação consistiu de 2,5 $\mathrm{mM}$ de $\mathrm{MgCl}_{2}$, tampão de PCR 1X, 0,1 mM de cada dNTP, 0,2 uM de cada oligonucleotideo e $1 \mathrm{U}$ de Taq DNA polimerase (Invitrogen), com volume final da mistura de 50 uL. A amplificação em termociclador gradiente (Eppendorf) consistiu de um passo de $95 \stackrel{\circ}{\circ} \mathrm{C}$ por 10 min., seguidos por 35 ciclos de 95 으 por 1 min., $61^{\circ} \mathrm{C}$ por $1 \mathrm{~min}$. e $72{ }^{\circ} \mathrm{C}$ por 90 seg. A reação foi finalizada com um passo de extensão final de $72 \stackrel{\circ}{\circ}$ por $10 \mathrm{~min}$. $\mathrm{O}$ produto da reação de amplificação foi analisado por eletroforese e visualizado sob luz ultravioleta em gel de agarose $1 \%$ com brometo de etídeo. Os exames foram realizados com controle negativo e positivo para validação, sendo o controle positivo um segmento do gene rRNA 16S confirmado por sequenciamento.

As amostras devidamente acondicionadas em caixa isotérmica com gelo tiveram 
o tempo de transporte de 36 horas até 0 laboratório. Os exames foram realizados no laboratório Microvet em Viçosa-MG.

\section{RESULTADOS}

Durante as avaliações clínicas realizadas nos dias 0,55 e 76 após a chegada dos animais não foram observados sinais clínicos sugestivos de problemas respiratórios, tais como espirro, tosse e dispneía. O funcionário responsável pela unidade de quarentena também não relatou tosse até os 76 dias, sendo esta observada por volta dos 90 dias após o alojamento.

As análises sorológicas realizadas nas amostras coletadas no dia 0 foram negativas enquanto que três amostras de soro coletadas no dia 55 após o alojamento apresentaram resultados não conclusivos (DO entre 50 a $65 \%$ do

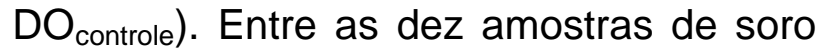
coletadas no dia 76 (três amostras de soro com resultados não conclusivos nas análises sorológicas do dia 55 e sete amostras de fêmeas em contato direto com estas três fêmeas), todas apresentaram resultados negativos (Tabela 1 ).

$\mathrm{Na}$ necropsia de uma das fêmeas com resultado não conclusivo na análise sorológica foi observada área de pneumonia, caracterizada por área de consolidação de coloração rósea púrpura em $50 \%$ do lobo cardíaco direito. O exame de PCR do pool de lavado traqueobronqueal e tecido pulmonar apresentaram resultado positivo para o $M$. hyopneumoniae.

\section{DISCUSSÃO}

A associação de exame sorológico com a técnica de PCR possibilitou a detecção do $M$. hyopneumoniae em uma leitoa, sem sinal clínico sugestivo de problema respiratório, durante procedimento de quarentena. Outros estudos também demonstraram a associação entre técnicas laboratoriais como forma de melhorar a sensibilidade de detecção do $M$. hyopneumoniae (Sorensen et al., 1997; Erlandson et al., 2005). A confirmação da infecção pelo Mycoplasma hyopneumoniae foi realizada por meio da PCR de lavado traqueobronqueal e de tecido pulmonar de fêmea com análise sorológica não conclusiva. Sendo assim, a análise sorológica foi importante na indicação de possíveis animais portadores assintomáticos ou com infecção subclínica.

Não foi detectado tosse e soroconversão até 76 dias após o alojamento. É importante ressaltar que sinais clínicos como tosse podem ser observados antes da soroconversão para o Mycoplasma hyopneumoniae (Sorensen et al., 1997; Fano et al., 2005), sendo, o período para soroconversão bastante variável (Sorensen et al., 1997). Em condições experimentais a soroconversão pode ocorrer entre 8 a 63 dias (Sorensen et al., 1997; Fano et al., 2005; Pieters et al., 2008), enquanto que, em condições de infecção natural esta pode ser de 35 a 125 dias pós-infecção (Leon et al., 2001; Fano et al., 2005). No presente estudo, os resultados obtidos demonstraram que 0 período para a observação de sinais clíni-

Tabela 1 - Resultados das análises sorológicas para Mycoplasma hyopneumoniae em fêmeas suínas durante procedimento de quarentena

\begin{tabular}{lccc}
\hline Dias após o alojamento & 0 & 55 & $76^{2}$ \\
\hline Número de amostras coletadas & 60 & 60 & 10 \\
Número de amostras $\mathrm{DO}^{1}>65 \%$ (negativas) & 60 & 57 & 10 \\
Número de amostras DO entre 50 a 65\% (não conclusivas) & 0 & 3 & 0 \\
Número de amostras DO $<50 \%$ (positivas) & 0 & 0 & 0 \\
\hline
\end{tabular}

${ }^{2}$ Três destas 10 amostras foram de animais com resultado não conclusivo no dia 55. 
cos e detecção do M. hyopneumoniae por meio de análises sorológicas pode ser maior que 76 dias. O relato de tosse aos 90 dias após o alojamento pode sugerir uma fase inicial da manifestação clínica da doença e posterior soroconversão. Estudos relataram soroconversão entre 9 a 13 dias após a observação de tosse em suínos infectados de forma experimental (Sorensen et al., 1997; Pieters et al., 2008). Pieters et al. (2008) relataram à disseminação do $M$. hyopneumoniae por animais infectados antes da observação de sinais clínicos como tosse.

O kit DAKO ELISA utilizado neste presente estudo está entre os mais consistentes em identificar suínos infectados (Thacker, 2006). Entretanto, Erlandson et al (2005) demonstraram valores de sensibilidade para este kit DAKO ELISA inferiores à relatada na literatura. Neste estudo, os autores avaliaram a sensibilidade e especificidade de três kits ELISA para o $M$. hyopneumoniae, sendo que, a combinação entre estes kits sorológicos foi sugerida como estratégia para melhorar a sensibilidade de detecção da infecção pelo Mycoplasma hyopneumoniae (Erlandson et al., 2005). Estudos demonstraram que anticorpos para o Mycoplasma flocculare podem apresentar reação cruzada em alguns kits sorológicos para Mycoplasma hyopneumoniae (Feld et al., 1992; Thacker, 2006).

No presente estudo optou-se pela eutanásia da fêmea para coleta de material e realização da técnica de PCR pois: (1) estudos demonstraram melhor sensibilidade na detecção do $M$. hyopneumoniae de brônquios e de tecido pulmonar em relação à suabe da cavidade nasal ou de tonsilas (Meyns et al., 2004; Sibila et al., 2007); (2) a técnica de lavado traqueobronqueal no animal vivo com procedimentos de anestesia pode ser utilizada, entretanto, Moorkamp et al. (2008) relataram que esta técnica no animal vivo pode não atingir a área do pulmão afetada pelo agente infeccioso; (3) em estágio inicial ou crônico da infecção o suíno pode ser soronegativo e $0 \quad M$. hyopneumoniae ser detectado pelo PCR (Sorensen et al. 1997; Pieters et al., 2008). Vale ainda ressaltar que Blanchard et al. (1996) relataram que a técnica de PCR apresenta boa sensibilidade para detectar - M. hyopneumoniae em lavado traqueobronqueal de suínos infectados de forma experimental, embora alguns animais infectados podem apresentar resultados negativos no PCR.

É importante ressaltar que um lote de reprodutores de alto valor genético apresenta maior custo de eutanásia de animais com fins de diagnóstico em relação a animais destinados ao abate. Por outro lado, deve-se considerar todo o investimento em medidas de biossegurança com o objetivo de evitar a contaminação do rebanho com o $M$. hyopneumoniae. Neste sentido, a eutanásia das outras duas fêmeas com resultados não conclusivos nas análises sorológicas poderia ser uma opção caso o resultado da PCR fosse negativo.

A lesão de consolidação pulmonar observada no lobo cardíaco direito (50\%) durante a necropsia não é suficiente para concluir o diagnóstico, pois outros agentes infecciosos, como o Mycoplasma hyorhinis, podem produzir lesões macroscópicas e histopatológicas semelhantes ao $M$. hyopneumoniae (Lin et al., 2006). Vale ainda ressaltar que o Mycoplasma hyopneumoniae pode ser detectado em amostras de pulmão sem lesões de pneumonia (Calsamiglia et al., 2000). Kich et al. (2007) também não relataram tosse em um suíno com extensa área de consolidação pulmonar no lobo cardíaco esquerdo (70\%).

Não foram realizadas avaliações clínicas ou exames laboratoriais na granja de origem dos animais deste lote. Maes et al. (2008) sugerem que avaliações no plantel de origem são fundamentais no processo de controle da contaminação do 
plantel de destino, uma vez que a forma de transmissão mais importante do $M$. hyopneumoniae ocorre através do contato direto, embora a transmissão indireta através de fômites pode ocorrer (Goodwin, 1985). Desta forma, apesar do isolamento desta área e das medidas de biossegurança adotadas na unidade de quarentena, não foi possível definir a origem do $M$. hyopneumoniae detectado.

O período entre o alojamento dos reprodutores e a detecção do $M$. hyopneumoniae neste presente estudo, bem como o período de soroconversão relatado em estudos recentes (Fano et al., 2005; Pieters et al., 2008) alertam para a necessidade de discussão sobre o período de quarentena praticado, entre 30 a 60 dias, em várias unidades de produção de suínos no Brasil. Segundo estes estudos, períodos de 90 a 120 dias podem ser necessários para a soroconversão. Vicca et al (2003) relataram que o curso da manifestação clínica da pneumonia enzoótica pode ser influenciado pelo manejo, condições de alojamento e diferença na virulência entre as amostras do Mycoplasma hyopneumoniae.

É importante uma melhor conscientização das equipes responsáveis pelos sistemas de produção de suínos sobre as vantagens e limitações das técnicas laboratoriais disponíveis para diagnóstico de $M$. hyopneumoniae (Blanchard et al., 1996; Sorensen et al., 1997; Calsamiglia et al., 2000; Erlandson et al., 2005; Sibila et al., 2007), bem como, das limitações sobre as informações de características do Mycoplasma hyopneumoniae (Fano et al., 2005), de forma que a interação entre equipes de produção, veterinários e laboratórios de diagnóstico possa executar protocolos de investigações necessários. Neste sentido, é fundamental que veterinários participem do planejamento de povoamento e reposição dos reprodutores para que os procedimentos de quarentena não tenham que se "adaptar" ao cronograma estabelecido pela área comercial.

\section{CONCLUSÕES}

A associação entre a análise sorológica e a reação em cadeia da polimerase (PCR) obteve sucesso no diagnóstico de Mycoplasma hyopneumoniae durante o procedimento de quarentena em um lote de reprodutores de suínos.

\section{REFERÊNCIAS}

ARTIUSHIN, S.; STIPKOVITS, L.; MINION, F.C. Development of polymerase chain reaction primers to detect Mycoplasma hyopneumoniae. Molecular and Cellular Probes, v.7, p.381-385, 1993.

BLANCHARD, B.; KOBISCH, M.; BOVÉ, J.M. et al. Polymerase chain reaction for Mycoplasma hyopneumoniae detection in tracheobronchiolar washings from pigs. Molecular and Cellular Probes, v.10, p.15-22, 1996.

CALSAMIGLIA, M.; COLLINS, J.; PIJOAN, C. Correlation between the presence of enzootic pneumonia lesions and detection of Mycoplasma hyopneumoniae in bronchial swabs by PCR. Veterinary Microbiology, v.76, p.299-303, 2000.

DAVIS, L.; KUEL, W.M.; BATTEY, F.J. Rapid Preparation of Genomic DNA from Tissue or Cultured Cells. In: Basic Methods in Molecular Biology. 2nd. ed. Norwalk: Appleton \& Lange, 1994. Cap.10-1, p.307-309.

ERLANDSON, K.; EVANS, R.; THACKER, B. et al. Evaluation of three serum antibody enzyme-linked immunosorbent assays for Mycoplasma hyopneumoniae. Journal of swine Health and production, v.13, p.198-203, 2005.

FANO, E.; PIJOAN, C.; DEE, S. Dynamics and persistence of Mycoplasma hyopneumoniae infection in pigs. The Canadian Journal of Veterinary Research, v.69, p.223-228, 2005.

FELD, N.C.; QVIST, P.; AHRENS, P. et al. A monoclonal blocking ELISA detecting serum antibodies to Mycoplasma hyopneumoniae. Veterinary Microbiology, v.30, p.35-46, 1992

GOODWIN, R. Apparent re-infection enzooticpneumonia free pig herds: search for possible causes. Veterinary Record, v.116, p.690-694, 1985

$\mathrm{KICH}$, J.D.; MORÉS, N.; TRIQUES, N.J. et al. A Pasteurella multocida tipo A Atuaria Como 
Agente Primário nos Processos Pneumônicos dos Suínos. 2007. (Comunicado Técnico, n. 469). Disponível em: http://www.cnpsa.embrapa.br/ Acesso em:14/12/2008

KIM, J.; CHUNG, H. -K.; CHAE, C. Association of porcine circovirus 2 with porcine respiratory disease complex. The Veterinary Journal, v. 166, p. 251256, 2003

LEON, E.A.; MADEC, F.; TAYLOR, N. et al. Seroepidemiology of Mycoplasma hyopneumoniae in pigs from farrow-to-finish farms. Veterinary Microbiology, v.78, p.331-341, 2001.

LIN, J.H.; CHEN, S.P.; YEH, K.S. et al. Mycoplasma hyorhinis in Taiwan: Diagnosis and isolation of swine pneumonia pathogen. Veterinary Microbiology, v.115, p.111-116, 2006.

MAES, D.; SEGALÉS, J.; MEYNS, T. et al. Control of Mycoplasma hyopneumoniae infections in pigs. Veterinary Microbiology, v.126, p.297-309, 2008

MATTSSON, J.G.; BERGETRON, K.; WALLGREN, $P$. et al. Detection of Mycoplasma hyopneumoniae in nose swabs from pigs by in vitro amplification of the $16 \mathrm{~S}$ rRNA gene. Journal of Clinical Microbiology, v.33, p.893-897, 1995.

MEYNS, T.; MAES, D.; DEWULF, J. et al. Quantification of the spread of Mycoplasma hyopbeumoniae in nursery pigs using transmission experiments. Preventive Veterinary Medicine, v.66, p.265-275, 2004.

MOORKAMP, L.; NATHUES, H.; SPERGSER, J. et al. Detection of respiratory pathogens in porcine lung tissue and lavage fluid. The Veterinary Journal, v.175, p.273-275, 2008.
PIETERS, M.; PIJOAN, C.; FANO, E. et al. An assessment of the duration of Mycoplasma hyopneumoniae infection in an experimentally infected population of pigs. Veterinary

Microbiology, v.134, p.261-266, 2008.

SIBILA, M.; NOFRARÍAS, M.; LÓPEZ-SORIA, S. et al. Chronological study of Mycoplasma hyopneumoniae infection, seroconversion and associated lung lesions in vaccinated and nonvaccinated pigs. Veterinary Microbiology, v.122, p.97-107, 2007.

SØRENSEN, V.; AHRENS, P.; BARFOD, P. et al. Mycoplasma hyopneumoniae infection in pigs: Duration of the disease and evaluation of four diagnostic assays. Veterinary Microbiology, v.54, p.23-34, 1997.

THACKER, E.L. Mycoplasmal Diseases. In: Straw B, D'Allaire S, Taylor D, Zimmerman J. Diseases of Swine. 9. ed. Ames, lowa: lowa State University Press, 2006, Cap. 42, p.701-717

THACKER, E.; HALBUR, P.G.; ROSS, R.F. et al. Mycoplasma hyopneumoniae potentiation of porcine reproductive and respiratory syndrome virusinduced pneumonia. Journal of Clinical Microbiology, v.37, p.620-627, 1999.

VICCA, J.; STAKENBORG, T.; MAES, D. et al. Evaluation of virulence of Mycoplasma hyopneumoniae field isolates. Veterinary Microbiology, v.97, p.177-190, 2003. 